\title{
THERAPEUTIC EFFICACY OF OXIME REACTIVATORS IN FENITROTHION TOXICITY IN BUFFALO CALVES (BUBALUS BUBALIS)
}

\author{
A. K. SRIVAStaVA* and J. K. MALIK ${ }^{+}$ \\ Department of Pharmacology and Toxicology, College of Veterinary Science, \\ Punjab Agricultural University, Ludhiana - 141 004, India
}

(Received April 27, 2000; accepted October 30, 2000)

\begin{abstract}
The therapeutic efficacy of 2-pyridine aldoxime methochloride and diacetylmonoxime (DAM) alone and in combination with atropine was determined in oral fenitrothion toxicity in buffalo calves. DAM alone and in combination with atropine constitute the most effective therapy of fenitrothion poisoning. As compared to 2-pyridine aldoxime methochloride, DAM was also more effective in reactivating the fenitrothion-inhibited erythrocyte and plasma acetylcholinesterase and serum carboxylesterase enzymes and reversing fenitrothion-induced hyperglycaemia, hyperproteinaemia and hypercreatinaemia in animals.
\end{abstract}

Key words: Therapeutic efficacy, oxime reactivator, fenitrothion toxicity, buffalo calves

Organophosphate insecticides (OPI) produce their pharmacological effects by inhibiting the acetylcholinesterase (AchE) enzyme (Srivastava et al., 1983; Srivastava and Malik, 1988a). The treatment of OPI toxicity includes oxime reactivators (acetylcholinesterase reactivators) in conjunction with atropine. Although oxime reactivators have been reported to control several toxic manifestations caused by OPIs (Hatch, 1982), there is less agreement on the choice of a particular oxime reactivator in OPI toxicity. Gupta (1984) demonstrated that 2PAM alone is of no therapeutic value in acute malathion poisoning in buffalo calves. However, there are still no sufficient data to establish the therapeutic efficacy of other oxime reactivators in the treatment of OPI toxicity. The purpose of the present investigation was to compare the therapeutic efficacy of oxime reactivators diacetylmonoxime (DAM) and 2-pyridine aldoxime (2-PAM) methochloride alone and in conjunction with atropine in acute toxicity of fenitrothion (FTH) in buffalo calves. In addition, in the present study, the reversal effects of these oxime reactivators on fenitrothion-induced biochemical alterations were also investigated.

\footnotetext{
* Corresponding author; Fax: +91 (0161) 400945, +91 (0161) 400822

${ }^{+}$Present address: Division of Pharmacology and Toxicology, Indian Veterinary Research Institute, Izatnagar, (UP) India
} 


\section{Materials and methods}

\section{Animals and treatment}

Twenty clinically healthy male buffalo calves weighing between 70 and $90 \mathrm{~kg}$, purchased from the local market, were used in the present study. All the animals were fasted for 16-20 h prior to administration of fenitrothion in a single oral lethal dose of $435 \mathrm{mg} / \mathrm{kg}$ body weight (Srivastava et al., 1984). The calves were randomly divided into 5 groups of 4 animals each. Immediately after the appearance of severe toxic symptoms, within $60 \mathrm{~min}$ of fenitrothion administration, the animals of Groups 1, 2, 3, 4 and 5 were treated with different antidotes as detailed in Table 1 . Doses of oxime reactivators $(8 \%)$ which refer to base and time for their repetition were chosen taking into account our previous work (Malik and Srivastava, 1987; Srivastava and Malik, 1989). For the purpose of combined administration, the animals were first injected atropine $(0.15 \%)$ followed by DAM and 2-PAM within $5 \mathrm{~min}$.

\section{Experimental procedure}

Blood samples were collected by jugular venipuncture in heparinised and non-heparinised glass test tubes prior to and at various time intervals after administration of therapeutic treatments. Plasma and serum were separated at room temperature soon after collection. Various biochemical parameters were measured on the day of collection. The activity of erythrocyte and plasma acetylcholinesterase was measured according to the method of Moroi et al. (1976). Serum carboxylesterase enzyme was measured by the method of Mandoza et al. (1971). Total serum protein and creatinine and blood glucose were determined by the method of Wootton (1964).

After the treatments, the regression coefficient in different groups of animals was calculated from the mean values of biochemical parameters as a function of time.

\section{Results and discussion}

In the present study, the acute toxicity of fenitrothion, one of the most commonly used organophosphate insecticides in India, was induced in buffalo calves by its single oral administration of $2 \times \mathrm{LD}_{50}$ dose. The dose of $435 \mathrm{mg} / \mathrm{kg}$ of fenitrothion was lethal to all buffalo calves within 8-12 h (Srivastava et al., 1984). The toxic signs of fenitrothion observed in the present study were not different from those reported with other OPIs (Hatch, 1982). The toxic symptoms which started 20-23 min after administration of fenitrothion progressed to their peak at $30-60 \mathrm{~min}$. 


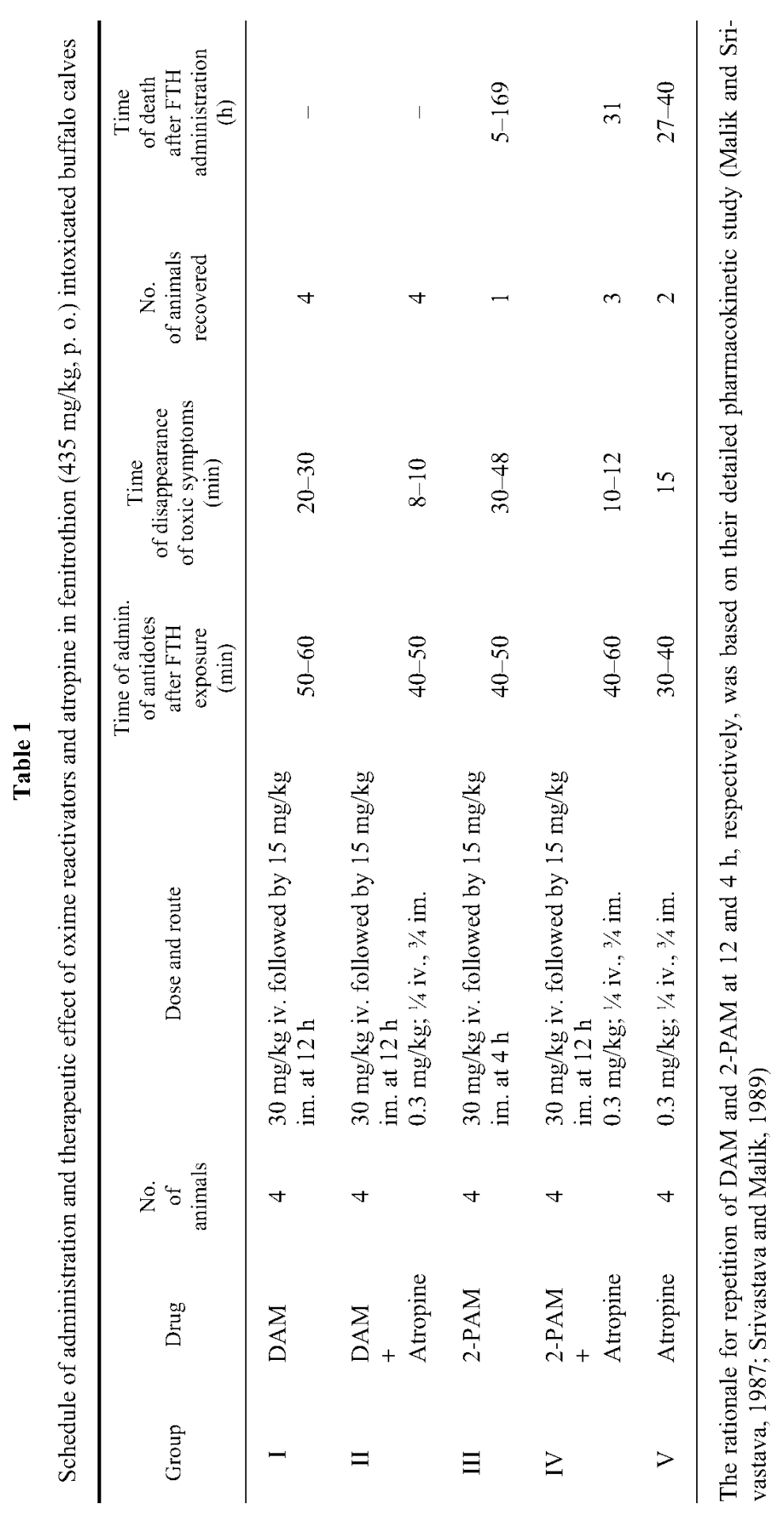


The therapeutic effects of various antidotes on fenitrothion-induced toxicity and lethality in buffalo calves are summarised in Table 1. Intravenous, followed by intramuscular, administration of DAM afforded complete protection in animals intoxicated with fenitrothion. The visible toxic symptoms disappeared within 20-30 min after the first dose of DAM. All the animals started ruminating after $12-14 \mathrm{~h}$ and appeared normal except that these animals were slightly depressed for $24 \mathrm{~h}$. The combined administration of DAM + atropine also protected $100 \%$ of the animals against fenitrothion-induced toxicity and lethality. The toxic symptoms disappeared within 8-10 min and animals became normal within 6$8 \mathrm{~h}$ and remained healthy during the period of study.

The administration of 2-PAM only partially protected animals against fenitrothion-induced toxicity and lethality. Out of four animals, two remained in comatose condition and died $5 \mathrm{~h}$ after the first injection of 2-PAM. One animal died on the 7th day of treatment, whereas another animal survived and remained apparently healthy thereafter. One out of four animals treated with 2-PAM + atropine died $30 \mathrm{~h}$ after institution of therapy. Other animals were protected but displayed slight generalised depression for 3 days. In contrast, 2-PAM alone or in combination with atropine has been reported to afford complete protection against lethality in organophosphate-poisoned cattle (Wright et al., 1966), sheep and goats (Younger and Radeleff, 1964). 2-PAM has, however, been reported to be of little or no therapeutic value in poisoning in animals due to schradon (Clarke et al., 1981) and malathion (Gupta, 1984). The single administration of atropine alone protected $50 \%$ of animals against fenitrothion poisoning.

Fenitrothion markedly depressed the activities of erythrocyte acetylcholinesterase, plasma acetylcholinesterase and serum carboxylesterase enzymes within 30 min of its exposure. The administration of DAM alone and in combination with atropine significantly reactivated erythrocyte and plasma acetylcholinesterase and serum carboxylesterase within $1 \mathrm{~h}$ after institution of therapy. Thereafter, the serum level of carboxylesterase increased above the normal control values. The administration of 2-PAM alone and in conjunction with atropine did not produce any effect on the level of serum carboxylesterase within $24 \mathrm{~h}$, whereas a slight reactivating effect of 2-PAM on erythrocyte and plasma AchE was observed during this period. The administration of atropine alone did not produce any reactivation of inhibited erythrocyte and plasma AchE, but in surviving animals self-reactivation of inhibited acetylcholinesterase was evident after $24 \mathrm{~h}$.

The rapid recovery of erythrocyte and plasma acetylcholinesterase following DAM administration, as compared to other antidotes, substantiates its greater antidotal efficacy. The marked protective effect and erythrocyte acetylcholinesterase reactivating potency of DAM observed in the present study in fenitrothion-poisoned buffalo calves was astonishing and is in contrast to the results of other workers, who reported very low therapeutic efficacy of DAM against organophosphate poisoning in rabbits (Gough and Shellenberger, 1978) 
and rats (Neef and Porsius, 1982). However, DAM has been demonstrated to be of therapeutic and protective value in diisopropyl-phosphorofluoridate poisoning in rats and rabbits (Ecobiochon, 1976), dichlorvos (Raina, 1984) and malathion (Srivastava, 1987) poisoning in buffalo calves. The relatively greater potency of DAM to reactivate carboxylesterase enzyme in buffalo calves is consistent with the results of Mayers (1959) and Ecobiochon (1976) who demonstrated that DAM was a potent reactivator of inhibited plasma carboxylesterase.

The administration of DAM alone was most effective in reversing the fenitrothion-induced hyperglycaemia, hyperproteinaemia and hypercreatinaemia. The lower efficacy shown by 2-PAM in reversing fenitrothion-induced hyperglycaemia in the present study is in agreement with the results of Matin and Siddique (1981).

The times required for these altered biochemical parameters to recover to their normal level following different antidotal treatment are given in Table 2. The comparative efficacy of these therapeutic treatments to reverse various fenitrothion-induced biochemical alterations, calculated on the basis of their regression coefficients, is given in Table 3.

\section{Table 2}

Recovery time (hours/days) of altered blood biochemical parameters to their normal values following administration of oxime reactivators and atropine in fenitrothion-poisoned buffalo calves

\begin{tabular}{|c|c|c|c|c|c|}
\hline \multirow{3}{*}{ Parameters } & \multicolumn{5}{|c|}{ Therapeutic treatments } \\
\hline & & DAM & & 2-PAM & \\
\hline & DAM & $\begin{array}{c}+ \\
\text { Atropine }\end{array}$ & 2-PAM & $\begin{array}{c}+ \\
\text { Atropine }\end{array}$ & Atropine \\
\hline Erythrocyte AchE & $12^{\mathrm{a}}$ & $12^{\mathrm{a}}$ & 21 & 21 & 28 \\
\hline Plasma AchE & 3 & 3 & 21 & 14 & 28 \\
\hline Serum carboxylesterase & $1^{\mathrm{a}}$ & $1^{\mathrm{a}}$ & 21 & 14 & 14 \\
\hline Serum protein & $6^{\mathrm{a}}$ & $6^{\mathrm{a}}$ & 21 & $24^{\mathrm{a}}$ & 14 \\
\hline Serum creatinine & $24^{\mathrm{a}}$ & 14 & 21 & 14 & 28 \\
\hline Blood glucose & $24^{\mathrm{a}}$ & 14 & 21 & 3 & 14 \\
\hline
\end{tabular}

Values are given in days after the first administration of antidote unless otherwise stated.

${ }^{a}$ Values are in hours

The results obtained with the various antidotes clearly indicated that DAM alone and in combination with atropine constitute the most effective therapy in the treatment of fenitrothion poisoning in the buffalo species. The greater therapeutic efficacy of DAM than 2-PAM in fenitrothion-poisoned buffalo calves may possibly be explained due to its (i) better reactivating effect on erythrocyte and plasma acetylcholinesterase and serum carboxylesterase enzymes, as established in the present study, (ii) greater penetration into the central nervous system and maintenance of high concentrations in the cerebrospinal fluid for a longer duration, as found in Bubalus bubalis (Srivastava et al., 1985), sheep (Srivastava et 
al., 1988) and heifers (Srivastava and Malik, 1988b), and (iii) maintenance of a therapeutic plasma concentration for a longer time as reported by Srivastava and Malik (1989).

Table 3

Comparative efficacy of oxime reactivators and atropine in reversing the blood biochemical parameters in fenitrothion-poisoned buffalo calves

\begin{tabular}{|c|c|}
\hline Parameter & Efficacy \\
\hline Erythrocyte AchE & $\mathrm{DAM}=\mathrm{DAM}+$ atropine $>2-\mathrm{PAM}=2-\mathrm{PAM}+$ atropine $>$ atropine \\
\hline Plasma AchE & $\mathrm{DAM}=\mathrm{DAM}+$ atropine $>2-\mathrm{PAM}+$ atropine $=2-\mathrm{PAM}>$ atropine \\
\hline Serum carboxylesterase & $\mathrm{DAM}+$ atropine $=\mathrm{DAM}>2-\mathrm{PAM}=2-\mathrm{PAM}+$ atropine $>$ atropine \\
\hline Serum protein & DAM $>2$-PAM + atropine $=$ DAM + atropine $=$ atropine $=2-\mathrm{PAM}$ \\
\hline Serum creatinine & $\mathrm{DAM}>\mathrm{DAM}+$ atropine $>2-\mathrm{PAM}=2-\mathrm{PAM}+$ atropine $>$ atropine \\
\hline Blood glucose & $\mathrm{DAM}=\mathrm{DAM}+$ Atropine $+2-\mathrm{PAM}+$ atropine $>$ atropine $>2$-PAM \\
\hline
\end{tabular}

\section{References}

Clarke, M. L., Harvey, D. G. and Humphreys, D. J. (1981): Veterinary Toxicology. 2nd edition. English Language Book Soc., London. pp. 146-156.

Ecobiochon, D. J. (1976): Species differences in the reactivation of organophosphate inhibited plasma esterases by diacetylmonoxime. Can. J. Physiol. Pharmacol. 54, 86-93.

Gough, B. J. and Shellenberger, T. E. (1978): In vivo inhibition of rabbit whole blood cholinesterase with organophosphate inhibitor and reactivation with oximes. Drug Chem. Toxicol. 1, $25-43$.

Gupta, R. C. (1984): Acute malathion toxicosis and related enzymatic alterations in Bubalus bubalis: Antidotal treatment with atropine, 2-PAM and idazepam. J. Toxicol. Environ. Health 14, 291-303.

Hatch, R. C. (1982): Poisons causing nervous stimulation or depression. In: Booth, N. H. and McDonald, L. E. (eds) Jone's Veterinary Pharmacology and Therapeutics. 5th edition, Kalyani Publ., New Delhi.

Malik, J. K. and Srivastava, A. K. (1987): Blood concentration of 2, 3-butanedione monoxime and some blood biochemical changes in Bubalus bubalis after intramuscular administration of this cholinesterase reactivator. Vet. Res. Commun. 11, 275-280.

Mandoza, C. E., Shields, J. B. and Phillips, W. E. J. (1971): Distribution of carboxylesterase activities in different tissues of albino rats. Comp. Biochem. Physiol. 40B, 841-854.

Matin, M. A. and Siddique, R. A. (1981): Role of cholinergic mechanism in hyperglycaemia induced by organophosphorous compounds. Indian J. Physiol. Pharmacol. 25, 104-105.

Mayers, D. K. (1959): Mechanism of the prophylactic action of diacetylmonoxime against sarin poisoning. Biochem. Biophys. Acta 34, 555-557.

Moroi, K., Ushiyana, S., Satoch, T. and Kuga, T. (1976): Enzyme induction by repeated administration of tetrachlorvinphos in rats. Toxicol. Appl. Pharmacol. 37, 377-386.

Neef De, J. H. and Porsius, A. J. (1982): The influence of obidoxime, diacetylmonoxime, pralidoxime and two less hydrophilic derivatives of pralidoxime upon the cholinesterase inhibition and the pressor effect by paraoxon in rats. Toxicol. Appl. Pharmacol. 55, 32-36.

Raina, R. (1984): Toxicological and biochemical studies of 2, 2-dichlorovinyl dimethyl phosphate (dichlorvos) in Bubalus bubalis, M.V.Sc. Thesis, Punjab Agricultural University, Ludhiana, India. 
Srivastava, A. K. (1987): Acute toxicity of malathion and its antidotal treatment with diacetylmonoxime and atropine in Bubalus bubalis. Environ. Pesticide Toxicol. 8, 235-241.

Srivastava, A. K. and Malik, J. K. (1988a): Effect of dichlorvos on tissue esterases in rats. J. Indian Inst. Sci. 68, 23-27.

Srivastava, A. K. and Malik, J. K. (1988b): Distribution of pyridine 2-aldoxime in blood, cerebrospinal fluids, interstitial fluid and urine of heifers. Indian Vet. J. 65, 310-313.

Srivastava, A. K. and Malik, J. K. (1989): Disposition kinetics of 2-pyridine aldoxime methochloride in Bubalus bubalis. J. Vet. Pharmacol. Therap. 12, 103-108.

Srivastava, A. K., Khanikor, H. N. and Malik, J. K. (1988): An experimental study on biodistribution of diacetymonoxime in sheep. Acta Veterinaria (Beograd) 57, 13-18.

Srivastava, A. K., Paul, B. S. and Malik, J. K. (1983): Effect of repeated oral administration of quinalphos on blood esterases in Bubalus bubalis. Toxicol. Lett. 19, 165-169.

Srivastava, A. K., Paul, B. S. and Malik, J. K. (1984): Comparative inhibition of blood cholinesterase and carboxylesterase in buffalo calves intoxicated with fenitrothion. Indian J. Pharmacol. 16, 60-61.

Srivastava, A. K., Paul, B. S. and Malik, J. K. (1985): Pharmacokinetics and tissue distribution studies of 2-pyridine aldoxime and diacetylmonoxime in buffalo calves. Indian J. Pharmacol. 17, 176-177.

Wootton, I. D. P. (1964): Microanalysis in Medical Biochemistry. 4th edition, J. and A. Churchill Ltd., London.

Wright, F. C., Hunt, L. M. and Palmer, J. S. (1966): The biochemical effects of coumaphos and three oximes on certain enzyme system and blood protein elements in cattle. Am. J. Vet. Res. 27, 177-185.

Younger, R. L. and Radeleff, R. D. (1964): Use of pyridine-2-aldoxime methochloride in the treatment of organic phosphorous compounds poisoning in livestock. Am. J. Vet. Res. 25, 981-986. 